\title{
A FATAL CASE OF PULMONARY ALVEOLAR PROTEINOSIS
}

\author{
BY \\ R. L. RAY AND R. SALM \\ From Tehidy Chest Hospital, Camborne, and Camborne-Redruth Hospital, Redruth, Cornwall
}

(RECEIVED FOR PUBLICATION SEPTEMBER 15, 1961)

Rosen, Castleman, and Liebow (1958) defined a "new" syndrome which they called pulmonary alveolar proteinosis, though it is surprising that the malady should have escaped the notice of competent workers of the past. They based their observations on a series of 27 cases ( 25 of which had been referred to them for opinion), 24 from the United States, and one each from Canada, Great Britain, and Italy.

According to these authors the disease occurred mainly in adults between the ages of 20 and 50 years ; their youngest patient was aged just over 2 years, their oldest 57 years. Males predominated in a proportion of $2.5: 1$. The illness frequently began suddenly with a pneumonia-like attack, which occasionally recurred, though sometimes the onset was gradual and insidious. After the initial attack the patient usually remained apyrexial. The main symptom was a progressive and ultimately crippling dyspnoea, though anorexia, lassitude, chest pain, cyanosis, and loss of weight were commonly present. Cough was noticed frequently, often unproductive, but sometimes "with a little white or yellowish sputum described as "chunky." Clubbing of the fingers was occasionally seen. Pulmonary function tests, though not normal, showed only moderate restrictive changes for most of the course, as well as evidence of an alveolar-capillary block. Polycythaemia with haemoglobin values above $100 \%$ was almost always found, occasionally accompanied by a polymorphic leucocytosis. The plasma lipids and proteins were within normal limits, electrophoresis results did not show any definite pattern, and serum electrolytes were normal.

Chest radiographs showed fine diffuse feathery or vaguely nodular opacities of moderate radioopacity, which tended to spread outwards from the hila not unlike pulmonary oedema and, when resolution occurred, regressed in the opposite direction. Pulmonary calcification and hilar glandular enlargement were never seen. All investigations for the presence of bacterial, fungal, viral, and protozoal infections and of chemical irritants, including radioactive material, were negative. The illness extended over months or years, and, of the original series of 27 , one-third improved, one-third remained stationary, and one-third had died within five years as the result of slowly progressive pulmonary insufficiency. Superadded infections such as nocardiosis and cryptococcosis were infrequent complications. Various forms of therapy were tried, but all proved ineffective.

At necropsy the lungs were the only diseased organs. They were bulky and heavy, weighing together between 2,950 and 3,500 g., due to numerous yellowish-grey, confluent nodular consolidations. The intervening lung tissue tended to be overexpanded. Microscopically alveoli and bronchioles in the involved areas were filled with a thick albuminous exudate which incorporated anisotropic acicular crystals. The lining alveolar cells were occasionally swollen, but there was very little cellular reaction in the alveolar walls, and no inflammatory cells or fibrin were found in the alveolar material. In frozen sections fat was demonstrable in the alveolar lining, in shed alveolar cells, and in interstitial macrophages. Chemical analyses of the lungs showed the lipid content to be increased up to six times the normal values (Table IV).

One of the cases of Rosen et al. (1958) had been contributed by Professor R. W. Scarff from the Middlesex Hospital, London, but the first cases fully recorded in this country with reviews of the literature were those of Hall (1960) and of Williams, Medley, and Brown (1960), whose patient suffered also from a hypoplastic anaemia associated with eosinophilia. Additional case reports have since been published, all in the United States (Table I). 
TABLE I

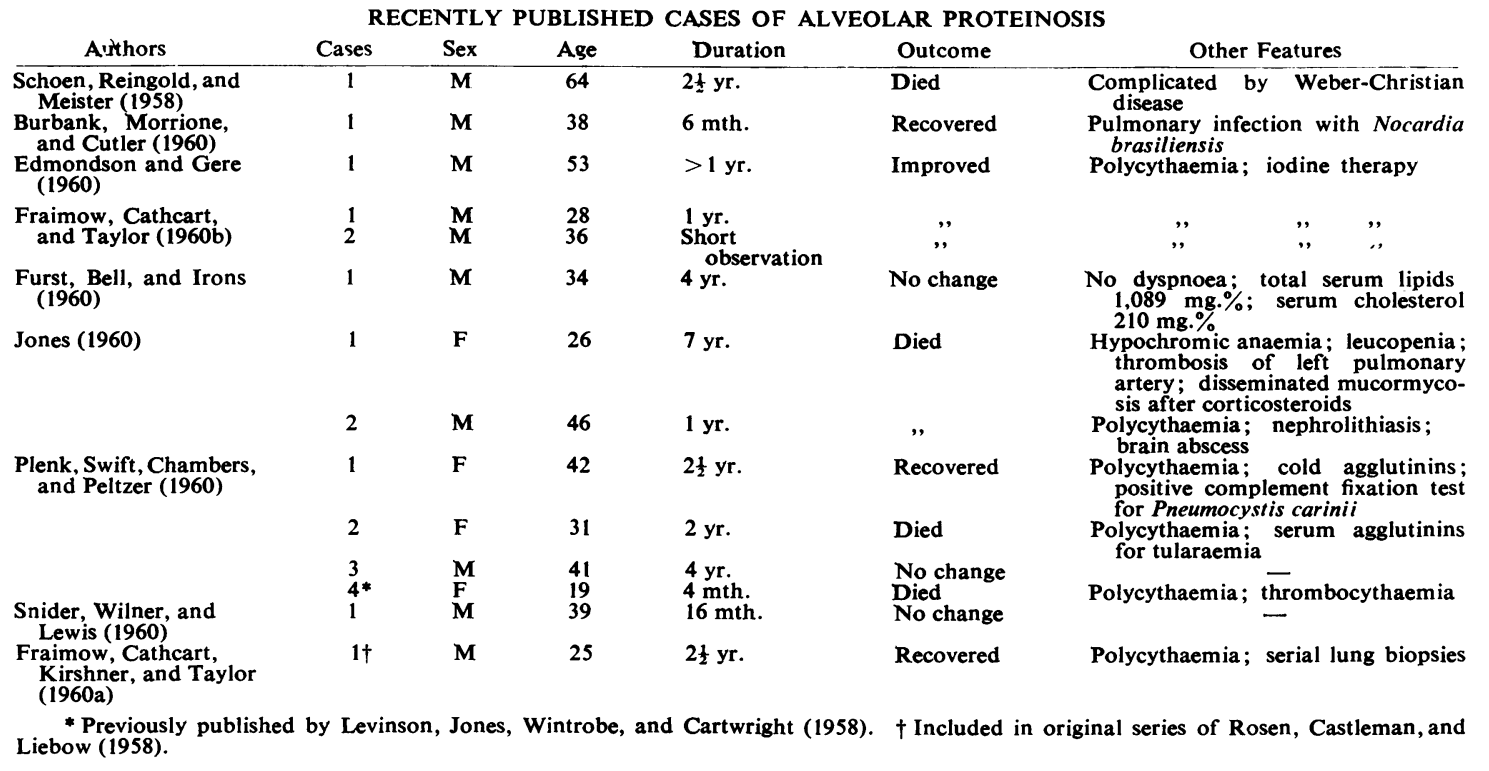

Some reports indicated the value of potassium iodide treatment, especially when used in large doses (McDowell, Williams, and Hinds, 1959 (up to 8 g. daily); Edmondson and Gere, 1960 ; and Fraimow, Cathcart, and Taylor, 1960b). The aetiology of the disease has remained obscure.

Up to now 45 cases have been reported. We wish to add another case from this country, and to draw the attention of clinicians and radiologists to the malady.

\section{CASE REPORT}

Previous History.-The patient, a previously healthy tin miner for 14 years, was first seen in December 1948, aged 34 years, when he gave a 12 months' history of paroxysmal attacks of cough productive of yellow sputum, gradually increasing dyspnoea, and left-sided chest pain. His weight then was $164 \mathrm{lb}$., he was slightly cyanosed, but there was no clubbing of the fingers and little in the way of chest signs. His chest radiograph was reported as showing changes consistent with early silicosis. Improving with symptomatic treatment he returned to work in the tin mines until February, 1955, when he was again referred with right-sided pleuritic pain and gradually increasing shortness of breath. Again his acute symptoms subsided rapidly, but a chest radiograph now showed diffuse nodulation fairly evenly distributed throughout both lung fields, with foci ranging from 2.5 to $7 \mathrm{~mm}$. across, and this appearance was considered consistent with silicosis stage II (Fig. 1). In February, 1956, a finer and more granular shadowing was seen involving mainly the mid-zones and perihilar areas, and this seemed either to beo replacing the initial nodulation or to be superimposed upon it. By January, 1957, the granular shadowing had become more radio-opaque and the vascular markings, though still just discernible, were becoming obscured (Fig. 2). By 1959 the radiographs showed the development of patchy opacities occupying mainly the mid and lower lung fields and apparently formed by confluence of the previous granular shadowing, but without any suggestion of hilar adenopathy. By this time he could not do even light work, and in March, 1960, he told us that he felt as if he were in a cast-iron waistcoat.

Now aged 45, he was overweight for his height at $182 \mathrm{lb}$., cyanosed, dyspnoeic, and hyperventilating on the slightest exertion; his fingers and toes showed second degree clubbing.

First Hospital Admission.-When admitted to hospital in March, 1960, he was afebrile, and crepitations were heard in both lower axillae, but no cardiological abnormalities were found. The blood pressure was $130 / 80$.

Repeated examinations of the scanty mucopurulent sputum failed to show the presence of any pathogens. His only haematological abnormality was a mild polycythaemia (Table II). The urine was normal. A positive Mantoux reaction was obtained both to old tuberculin and to a bovine antigen, while a Kveim test, using a potent antigen, was negative. Pulmometer readings showed some overall restriction of function without evidence of airway obstruction (Table III). An electrocardiograph showed changes over the right side of the heart consistent with pulmonary hypertension. 


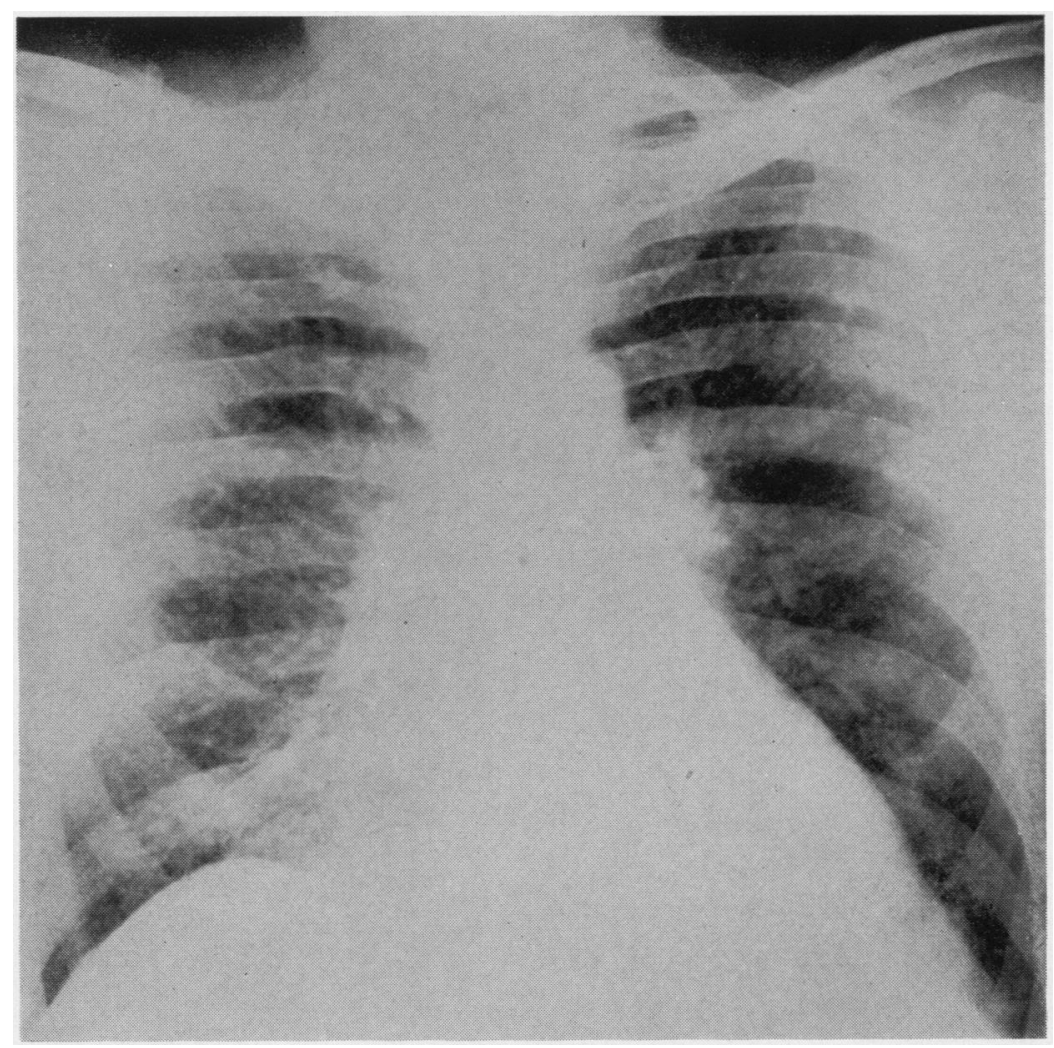

FIG. 1.-Chest radiograph taken March 24, 1955.

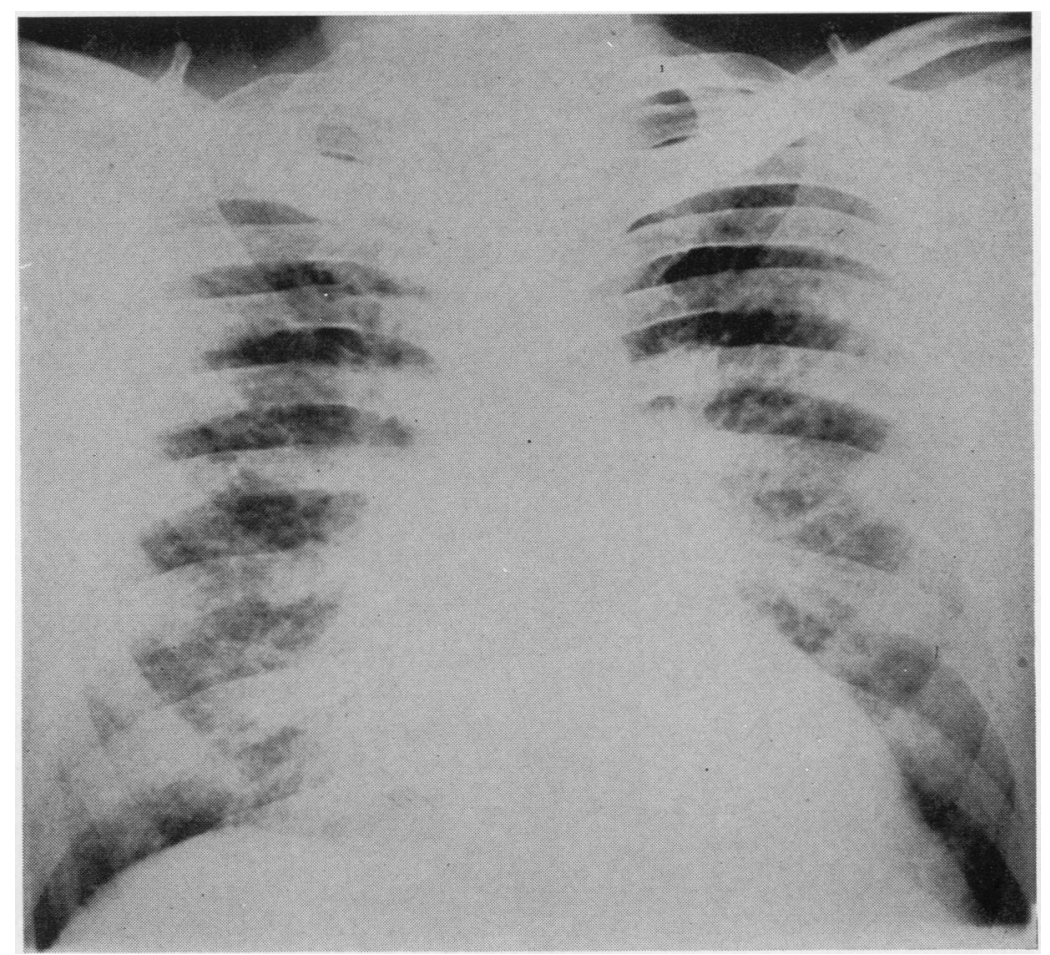

Fig. 2.-Chest radiograph taken January 21, 1957. 
TABLE II

\begin{tabular}{|c|c|c|c|c|}
\hline \multicolumn{5}{|c|}{ PULMOMETER READINGS } \\
\hline Date & $\begin{array}{c}\text { Vital } \\
\text { Capacity } \\
\text { (1.) }\end{array}$ & $\begin{array}{l}\text { Maximum } \\
\text { Breathing } \\
\text { Capacity } \\
\text { (1. min.) }\end{array}$ & $\begin{array}{l}\text { Percentage } \\
\text { of V.C. } \\
\text { per } \\
\text { Second } \\
\text { (1.) }\end{array}$ & $\begin{array}{c}\text { Peak } \\
\text { Expiratory } \\
\text { Flow per } \\
\text { Minute } \\
\text { (1.) }\end{array}$ \\
\hline December, 1948 & s & & & \\
\hline April, 1960 & & 70 & 92 & 460 \\
\hline August, 1960 & & (114) & 85 & \\
\hline November, 1960 & $\begin{array}{l}(4.65) \\
2 \cdot 2 \\
(4.55)\end{array}$ & $\begin{array}{c}68 \\
(113)\end{array}$ & 80 & 455 \\
\hline
\end{tabular}

TABLE III

RESULTS OF BLOOD EXAMINATION

\begin{tabular}{|c|c|c|c|c|c|}
\hline Date & $\begin{array}{l}\mathrm{Hb} \\
(\%)\end{array}$ & R.B.C. & W.B.C. & $\begin{array}{l}\text { P.C.V. } \\
\text { (\%) }\end{array}$ & $\begin{array}{c}\text { E.S.R. } \\
\text { (mm. } \\
\text { hr. }\end{array}$ \\
\hline $\begin{array}{l}\text { March 23,1960 } \\
\text { April 7, 1960 }\end{array}$ & 110 & - & 8,800 & 二 & $\begin{array}{l}4 \\
3\end{array}$ \\
\hline ovember 15,1960 & 100 & & 12,000 & 二 & - \\
\hline $\begin{array}{l}\text { November } 25,1960 \\
\text { January } 2,1961\end{array}$ & 116 & $\begin{array}{l}5,700,000 \\
5,62000\end{array}$ & 10,000 & $\bar{z}$ & 4 \\
\hline nuary 4,19 & 135 & $6,480,000$ & 9,300 & 62 & \\
\hline
\end{tabular}

Progress.-There was some improvement with symptomatic treatment, but there was no radiological change. By April, 1960, he had become sufficiently well to discharge himself, and he was followed up as an out-patient. He was still very dyspnoeic on exertion, but the slight symptomatic improvement was maintained until June, 1960, when attacks of paroxysmal unproductive cough recurred, often culminating in jactitations and transitory loss of consciousness.

He had gained weight (195 lb.), cyanosis had increased, and clubbing of the fingers and toes had become more pronounced. Radiologically the confluent shadowing in the perihilar areas and lower zones appeared more radio-opaque and extensive than before, and readmission to hospital was advised.

SECOND Hospital Admission.-Sputum examinations in July, 1960, again failed to demonstrate any pathogens and the serum proteins showed no significant deviation from normal. A bronchogram did not contribute much further information, but in the lower third of the lung fields, where the parenchymal shadowing was maximal, there was wellmarked pooling of the contrast medium in the terminal bronchioles.

Treatment.-We thought that his continuing deterioration justified a trial of steroid therapy combined with anti-tuberculous drugs. He received $1 \mathrm{~g}$. of streptomycin sulphate, $200 \mathrm{mg}$. of isoniazid, and 12 g. of P.A.S. daily, accompanied, to begin with, by prednisolone $40 \mathrm{mg}$. daily, the dose being reduced gradually to $10 \mathrm{mg}$. a day. When discharged in August, 1960, he felt better and showed an improved exercise tolerance; probably this was due to the loss of $18 \mathrm{lb}$. as a result of a weight-reducing diet. There was no corresponding radiological remission.

Progress.-Despite further weight reduction (to $168 \mathrm{lb}$. in September, 1960) both the exertional dyspnoea and the cyanosis continued to increase without evidence of any underlying congestive failure. By the end of 1960 he was even more short of breath and developed spasmodic cramps in the legs at night. Clinically his osteoarthropathy was more marked and there were crepitations over the right lower chest. We thought that a simple infection might be present, in addition to a hitherto undetected fungal infection, and so one of the combined tetracyn-nystatin compounds was given and the corticosteroid dosage increased. He was also given an oral diuretic since we could not exclude some pulmonary congestion. Nevertheless, he deteriorated fairly rapidly and was once again admitted to hospital in November, 1960.

Third (and Final) Hospital Admission.- He remained afebrile with the physical signs already noted and once again the pathological investigations were not contributory. Screening showed normal diaphragmatic excursion but paradoxical movement of the apparent consolidation at the right base. Such changes in heart outline as could be determined through the dense parenchymal shadowing (Fig. 3) were those of right ventricular enlargement.

Progress.-His condition continued to deteriorate and profuse bilateral basal crepitations developed. There was no response to diuretics. A further blood count showed progressive polycythaemia and, for the first time, a true tetanic spasm involving the fingers was observed, the serum calcium being normal. The patient was too ill for lung biopsy, and in January, 1961, he died during an attack of respiratory insufficiency.

\section{NECROPSY}

Necropsy was carried out 18 hours after death (Dr. Hocking). The body was that of a wellnourished middle-aged man with deeply cyanotic skin, some finger clubbing, and some ankle oedema. About $100 \mathrm{ml}$. of clear serous fluid was present in each pleural sac. The heart was about twice the normal size and dilated. After fixation it weighed $360 \mathrm{~g}$., the wall of the left ventricle measuring $1.7 \mathrm{~cm}$. and that of the right $1 \mathrm{~cm}$. in diameter. Cusps, valves, and coronary arteries were normal. The abdominal organs were normal except for the adrenals, which were reduced to about one-third of their normal size.

RESPIRATORY SYSTEM.-The bronchial tree was healthy. The lungs were normal in shape, greatly increased in size, mainly greyish but partly dark red in colour, and firm in consistency. The left lung weighed $1,300 \mathrm{~g}$. (normal 420 to $600 \mathrm{~g}$.), the right $1,450 \mathrm{~g}$. (normal 480 to $680 \mathrm{~g}$.). The pleurae were smooth and shiny. On sectioning, most of the lung parenchyma was airless, being occupied by large, greyish, firm areas of consolidation displaying fairly sharp margins (Fig. 4). In some areas they appeared to have arisen from fusion of 
FIG. 3.-Chest radiograph taken Ostobar 26, 1960.

FIG. 4.-Sagittal section through left lower lob?, showing nodular, part.y confluent areas of conso'idation, often displaying sharp'y demarcated margins.

FIG. 5.-Giant sagittal section through right lower lobe showing massive consolidation, with small scattered areas of uninvolved but emphysemato:s lung parenchyma.

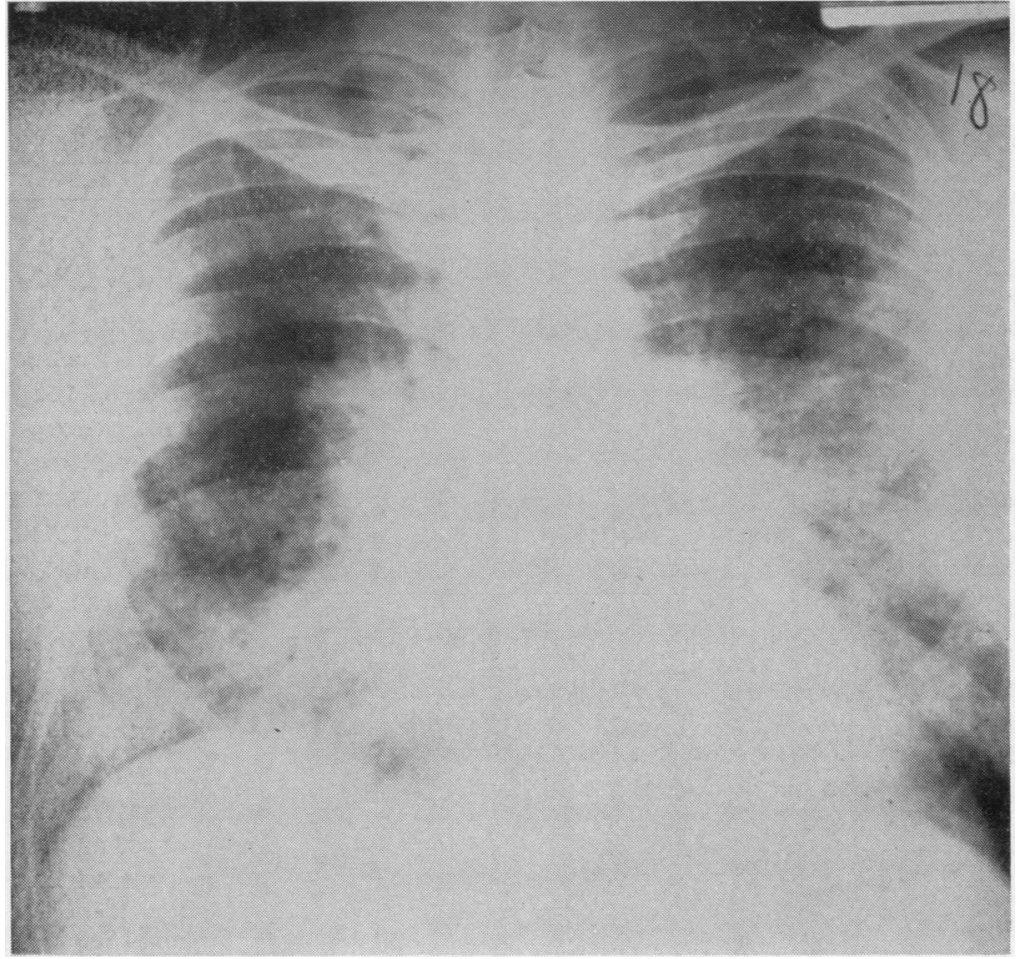

FIG. 3

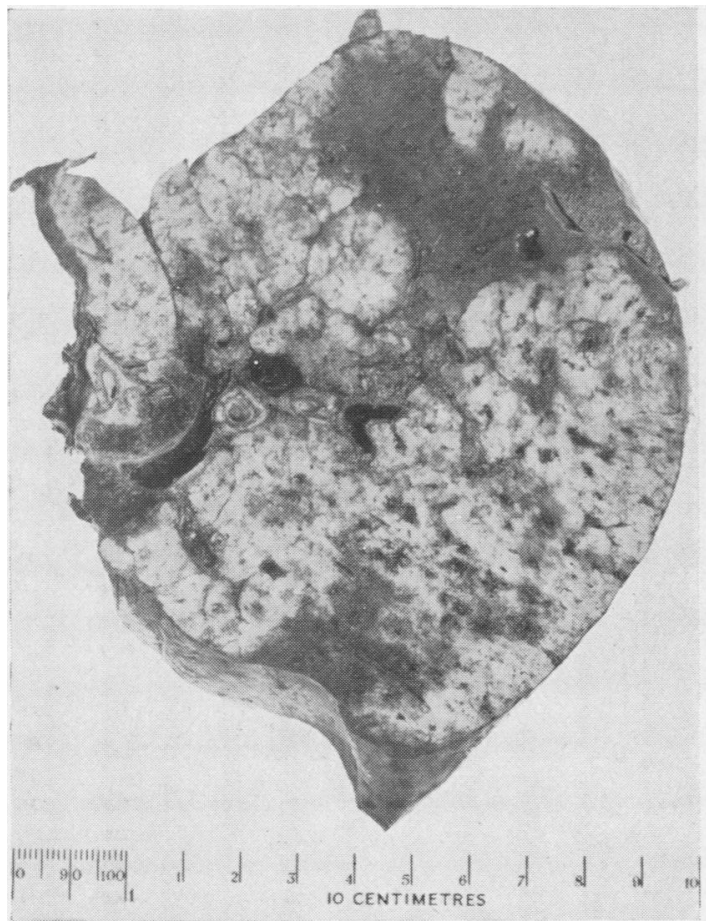

FIG. 4

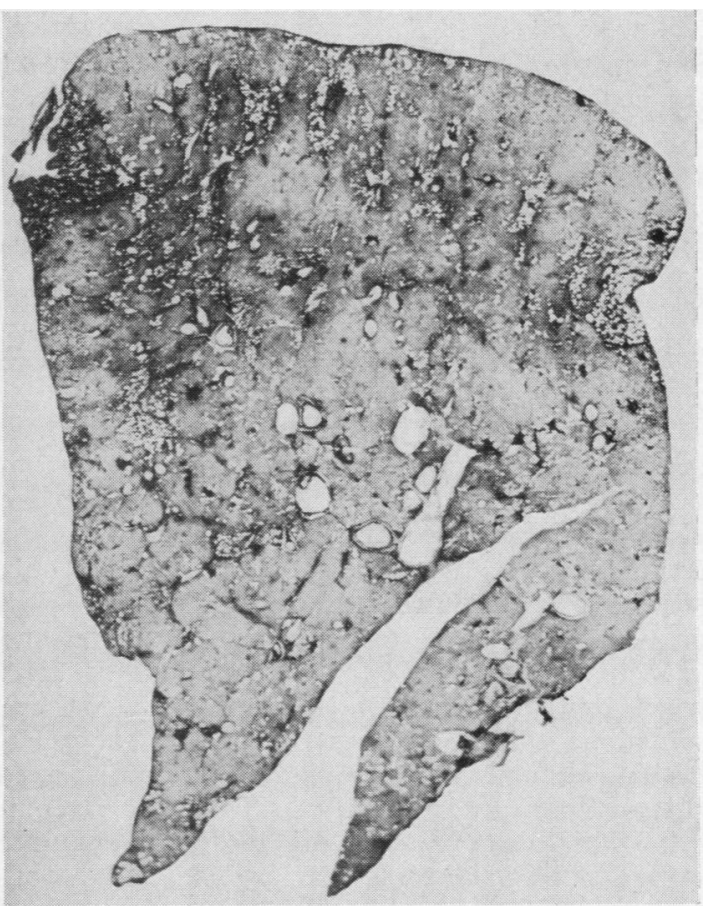

FIG. 5 
TABLE IV

CHEMICAL ANALYSIS OF LUNG (PERCENTAGE OF DRIED WEIGHT)

\begin{tabular}{|c|c|c|c|c|c|c|c|}
\hline \multirow{2}{*}{ Authors } & & \multicolumn{3}{|c|}{ Alveolar Proteinosis } & \multicolumn{3}{|c|}{ Normal Lung } \\
\hline & & Lipids & Cholesterol & Protein & Lipids & Cholesterol & Protein \\
\hline $\begin{array}{l}\text { Rosen, Castleman, and } \\
\text { Liebow (1958) } \\
\text { Present investigation (1961) }\end{array}$ & $\begin{array}{l}\text { Case } 1 \\
\text { Case } 2\end{array}$ & $\begin{array}{l}21 \cdot 9 \\
16 \cdot 1 \\
20\end{array}$ & $\begin{array}{c}\text { Not done } \\
\text { ", }\end{array}$ & $\begin{array}{l}64 \cdot 9 \\
64 \cdot 0 \\
60\end{array}$ & $\begin{array}{l}3 \cdot 4 \\
7\end{array}$ & $\begin{array}{c}\text { Not done } \\
1\end{array}$ & $\begin{array}{l}82 \cdot 4 \\
80\end{array}$ \\
\hline
\end{tabular}

nodular structures, in others consolidation was diffuse and extensive (Fig. 5). Very little uninvolved though congested parenchyma was discernible, estimated at less than $10 \%$. There was no evidence of silicosis. The pulmonary arteries and their main branches were patent, but some smaller peripheral arteries were occluded by fresh thrombi. The hilar lymph glands were quite small and inconspicuous.

Chemical Analysis of Lung.-Pieces of lung were dried and, together with similarly treated sections of normal lung, examined for lipids and proteins. The results are given in Table IV. These are comparable to those obtained by other workers, and demonstrate the considerable increase in neutral fat and also in cholesterol, whilst the protein values were correspondingly reduced.

Spectroscopical Analysis of Ashed Lung.Beryllium was absent (concentration below 10 to 20 p.p.m.) ; cobalt was absent (concentration below 5 to 10 p.p.m.) ; lead was absent (concentration below 10 to 15 p.p.m.); tin was present (concentration 20 to 40 p.p.m., normal values not detectable); and molybdenum was present (concentration 15 to 30 p.p.m., normal values not detectable).

Check of Radioactivity.-The lungs were scanned with a ratemeter, but no radioactivity was demonstrable.

Microscopical Examination (61/38).-Multiple blocks were cut from central and peripheral areas of all lobes. The pleurae were normal. The uninvolved parenchyma displayed severe compensatory emphysema (Fig. 5). All sections from the diseased areas showed identical features. The alveolar walls were usually intact and only occasionally disrupted, resulting in fusion of two or more alveoli (Fig. 6). The alveolar spaces and bronchioles were filled with albuminous fluid which, at the periphery of the involved areas, was sometimes thin and granular (Fig. 7), but otherwise thick and inspissated, and often displayed sharply defined peripheral margins. The alveolar cells were usually flat and inconspicuous, but occasionally were somewhat swollen and prominent. The alveolar walls were thin and free from cellular exudate. Frozen sections demonstrated patches of massed interstitial lipophages (Fig. 8), and some of the desquamated alveolar cells also contained isotropic fat droplets, but practically no lipid was present in the lining alveolar cells. The alveoli contained many, sometimes even numerous anisotropic crystals (Fig. 8), usually acicular in shape and sometimes arranged in bundles. Here and there the crystals were lying within fibrous septa, presumably due to localized breakdown of the tissues, and had provoked a foreign-body reaction with prominent multinucleated giant cells. The crystals were soluble in benzene and chloroform, insoluble in alcohol, acids, and alkalis, and gave negative Ehrlich and Schultz reactions. In frozen sections stained for fat, minute fat droplets were sometimes visible amongst the alveolar

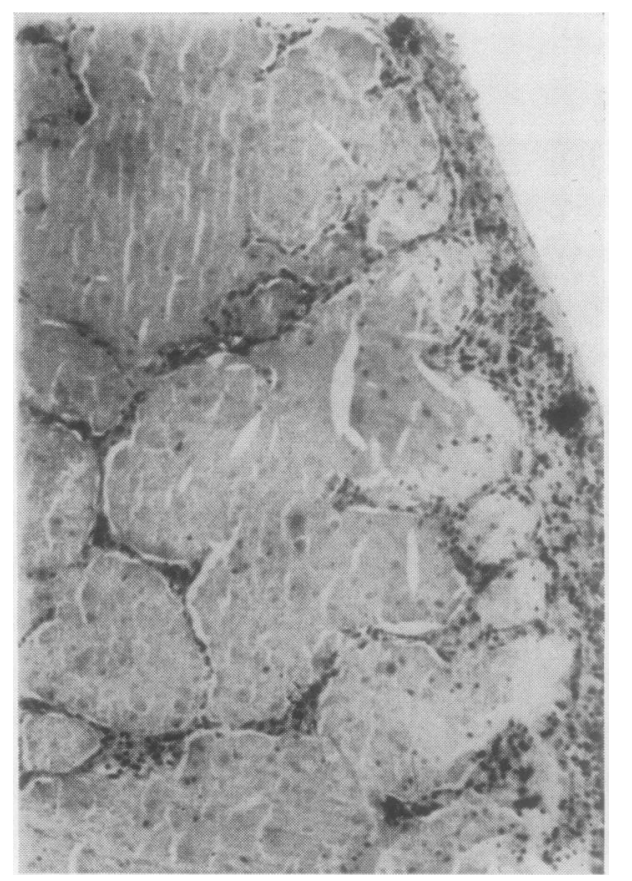

FIG. 6.-Peripheral part of lung covered by congested pleura. Alveoli filled with thick proteinaceous material incorporating crystal clefts. Alveolar walls occasionally disrupted. (Haematoxylin and eosin $\times 77$.) 


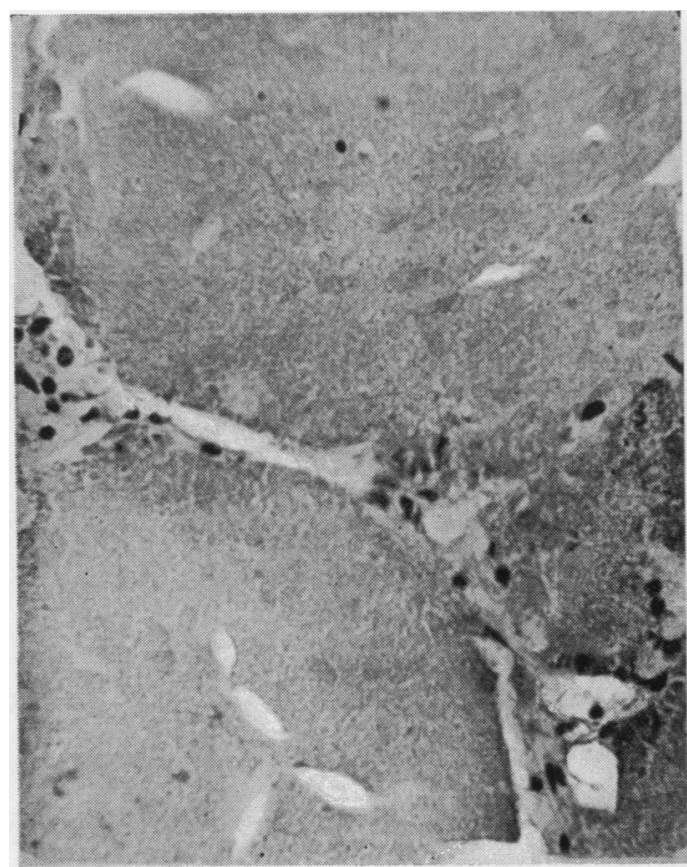

FIG. 7

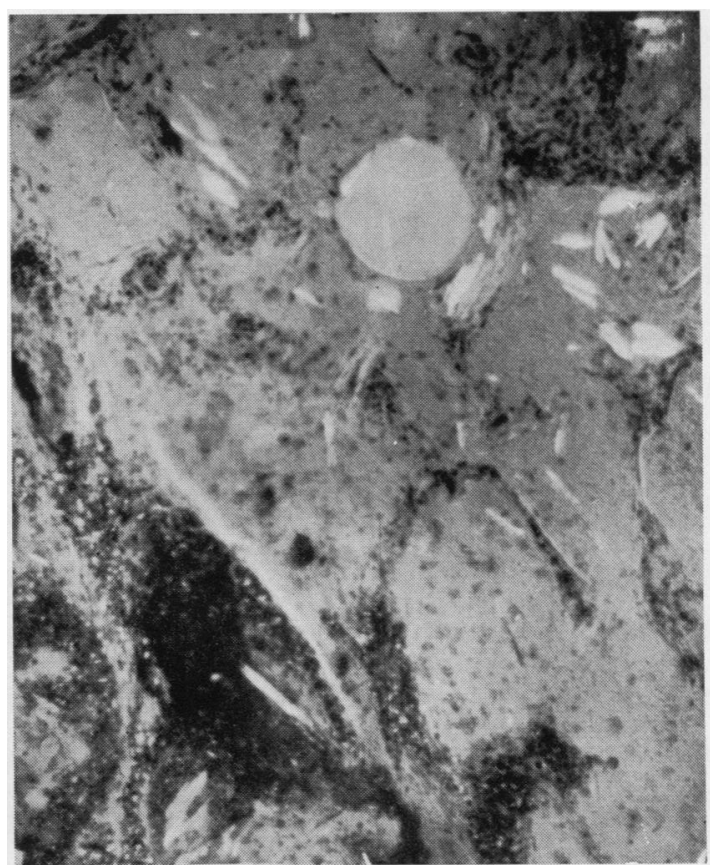

FIG. 8

FIG. 7.-High-power view showing thin, compressed alveolar walls, crystal clefts, and granular nature of intra-alveolar material. (Periodic acid-Schiff $\times 410$.)

FIG. 8.-Periphery of fib:ous area with massive concentration of lipophages, taken with half-crossed Nicol's prisms, demonstrating the numerous anisotropic crystals. Note also fat in cells along alveolar walls and within alveolar lumina. (Sudan III $\times 380$.)

material with the high power, whilst in some areas the alveolar contents as a whole assumed a very pale yellow-orange hue. The proteinaceous alveolar material was P.A.S.-positive, the intensity of the stain varying in different areas from pink to dark red, and the reaction was diastase-stable. No fibrin or iron pigment was demonstrable with special stains. Sections stained with Methasol fast blue 2G (Pearse, 1955) were largely negative for phospholipids. Some shed alveolar macrophages and inspissated parts of the alveolar material showed some affinity towards the dye, but the crystals were not stained.

In four out of 20 blocks cut from various areas of both lungs, small arterial branches were found to be occluded by recent largely hyaline platelet thrombi, but no older thrombotic lesions were discovered. In most areas the small blood vessels of the pulmonary septa were distended and gorged with blood, but the capillaries of the alveolar walls were of very small calibre and had to be searched for in routine stains, due to compression by the proteinaceous alveolar material.
Sections stained according to Gram, Giemsa, Ziehl-Neelsen and with alcian blue, phloxinetartrazine, mucicarmine, and methenamine-silver yielded no further information, and bacteria, fungi, inclusion bodies, and structures resembling Pneumocystis carinii were absent.

The hilar lymph nodes were normal in structure, oedematous, and anthracotic, but did not contain any P.A.S.-positive material.

Sections cut from the left and right ventricles, kidneys, spleen, and adrenals showed little of note except congestion, though the adrenals displayed narrow cortices.

\section{Discussion}

The diagnosis of pulmonary alveolar proteinosis is difficult without a lung biopsy, but a basic pattern common to all reported cases is now emerging. The finding of a " chunky" sputum, which on histological examination proved to be acellular, P.A.S.-positive, and incorporated acicular crystal spaces, was put forward by Carlson and Mason (1960) as important supportive 
evidence. Most of the features of our case were similar to those recorded in the literature. The description by Rosen et al. (1958) of the illness as an "unheralded and creepingly progressive dyspnoea" was amply fulfilled, though in our patient this process was observed over 12 years, a longer period than had hitherto been recorded. The dyspnoea was disproportionate to the relative absence of physical signs. Such signs as were present ranged from a few crepitations in one axilla to coarse crackling sounds at both bases. These signs were much the same as those described by other authors, as was the cyanosis and hyperventilation at rest, which were only partly relieved by oxygen. The clubbing of the fingers and toes, the polycythaemia (with no eosinophilia), the pulmonary hypertension, and the reduction in total and maximal breathing capacity on pulmometry, without evidence of airway obstruction, were all typical.

We were fortunate in having reports on films as far back as 1948 and the actual plates from 1955 onwards. On these the coarse nodulation was fairly evenly distributed throughout all zones and composed of opacities ranging from 0.25 to 0.7 $\mathrm{cm}$. in diameter. Their distribution suggested a close relationship to the pulmonary vessels, which at that stage were traceable without difficulty. This radiological picture persisted without much change until the onset of clinical deterioration in 1956, when the fine granular shadowing began to obscure the previously clear pulmonary vascular markings. These, together with residual coarse nodulation, faded progressively as the disease pursued its course. One or two of the original nodular shadows were, however, still visible towards the apices, areas reported to be frequently spared by the proteinaceous deposits (Fraimow, Cathcart, and Taylor, 1960b). The effect was that of a fine granular shadowing with patchy coalescence gradually "swamping" the nodulation which was seen initially.

In line with all other cases recorded, neither antibiotics (including nystatin) nor steroids produced any real benefit, though the former were symptomatically valuable for the bouts of superadded infection to which the patient was prone, and some subjective benefit could perhaps have been attributed to the latter. The use of potassium iodide is of considerable interest as, in addition to any possible antimycotic action, this drug is said to possess the property of liquefying bronchial, and presumably also intra-alveolar, secretion and so aiding its removal. Similarly, some symptomatic benefit might be anticipated from the use of streptokinase-streptodornase or trypsin by aerosol, or trypsin systemically. Diuretics, on the supposition that there was some pulmonary oedema, would be contraindicated unless unequivocal right heart failure supervened. Conceivably some light may be thrown on the mechanism by which the intra-alveolar exudate is produced by future studies with tagged proteins or lipids.

One other point of clinical interest is the wellmarked clubbing in the absence of any infection, and the fact that this is reversible (Fraimow, Cathcart, Kirshner, and Taylor, 1960a). Hall (1959) regarded finger clubbing as being due to the passage of pulmonary blood, still containing reduced ferritin, into the systemic circulation. In pulmonary alveolar proteinosis, although the alveolar capillaries remain largely patent, the inspissated alveoli can have no oxygenating action and so they produce what is in effect a venousarterial shunt. Resolution of alveolar contents, by once again allowing normal oxygenation of the venous blood, reverses this process.

At first we did not know why our patient experienced cramps, but the development later of a frank tetanic spasm of the hands suggested that the basic cause was the alkalosis induced by hyperventilation.

Since our patient was a tin miner, silicosis was first suspected and only finally excluded at necropsy. Berylliosis was at one time considered, since inquiries revealed beryllium to be present in the lode where the patient had been working; however, none of the other miners had any similar complaints. Moreover, beryllium does not cause the signs and symptoms found in our patient, and beryllium, cobalt, and lead were found to be absent on spectroscopy. Tuberculosis was ruled out ; sarcoidosis was seriously considered, but the absence of enlarged hilar lymph nodes and of any other manifestations made this diagnosis unlikely. Against the presence of an alveolar cell carcinoma was the long duration and the absence of copious bronchial secretion.

As in many other cases, the diagnosis in our patient was established only after death, when the macroscopical and microscopical features were typical. Like other workers, we failed to demonstrate a cellular reaction, fibrin, bacteria, fungi, protozoa, or inclusion bodies. Most impressive was the presence of large numbers of needleshaped crystals, which were soluble in organic solvents but gave a negative histochemical reaction for cholesterol and phospholipids. Jones (1960) likewise found the crystals to give a nega- 
tive reaction for cholesterol, but our results with the methasol stain are at variance with his.

The aetiology of the condition is quite obscure. A single toxic inhalant can be ruled out on account of the very varied occupations of the recorded cases. Plenk, Swift, Chambers, and Peltzer (1960) submitted the serum of their surviving patient for a Pneumocystis carinii complement fixation test. When this was repeatedly found to be positive, they arranged for the examination of sera from eight other survivors. Three of these proved to be positive, but in five the result was negative. These findings do not support the presence of a pneumocystis infection. Besides, as the authors themselves point out, there are histological differences. In alveolar proteinosis the exudate is granular and inflammatory cells are largely absent. In pneumocystis infection the alveolar exudate is foamy, the alveolar walls are infiltrated with predominantly plasma cells, and parasites are demonstrable with special techniques. Probably the positive findings in four out of nine patients were incidental only and signify no more than a positive Mantoux or other skin reaction or the agglutination titre of $1: 200$ for tularaemia in another of the authors' cases.

Rosen et al. (1958) postulated that the alveolar material was being secreted by the alveolar cells, as they had sometimes found P.A.S.-positive globules within the cytoplasm of alveolar cells. But this observation can equally well be interpreted as phagocytosis, and we agree with Plenk et al. (1960) and Snider, Wilner, and Lewis (1960), who doubt the origin of the alveolar material by active secretion. We regard it as most unlikely that the large amounts of this material could originate in this way, and support the view that it constitutes no more than possibly abnormal or unusual serum proteins and other serum constituents, which reach the alveoli as a passive transudate. In the alveoli the fluid in time inspissates, as shown by its increasing density and affinity towards the P.A.S. stain, and presumably one constituent crystallizes out in the shape of acicular crystals. The process is a reversible one leaving fairly normal lung tissue after regression, presumably by absorption: this has been shown by Fraimow et al. (1960a) by serial lung biopsy.

The thrombosis of a number of small branches of the pulmonary arteries was of recent date and no doubt terminal, most likely the result of the combined effects of polycythaemia and pulmonary consolidation.
Retrograde admixture of bronchial mucins (Hamperl, 1947) might be in part responsible for the positive P.A.S. stain, although the uniform distribution of mucopolysaccharides makes this unlikely. The two other constituents, lipids and proteins, make up much of the alveolar material, so that it would strictly be more correct to speak of alveolar lipid proteinosis. However, we think it is better to use the more conventional designation in order to avoid confusion with the UrbachWiethe syndrome (lipoid proteinosis) which involves skin, oral mucosa, and larynx.

Several authors have emphasized the similarity between uraemic pulmonary oedema and pulmonary alveolar proteinosis with regard to its mode of spread outward from the hilar areas. Borgström, Ising, Linder, and Lunderquist (1960), by increasing the permeability of the pulmonary capillaries, have produced a not dissimilar lung picture experimentally in dogs, which they termed " pulmonary capillary (alveolar) oedema." This also seems to support the working hypothesis of an intrinsic exudate due to vascular damage.

\section{SUMMARY}

A fatal case of pulmonary alveolar proteinosis is described, the third to be recorded in this country. The relevant literature is briefly reviewed. Chemical analysis and histological examination demonstrated a high content of lipid in the alveolar material, which we think is a passive transudate of serum constituents through the walls of the pulmonary vessels whose permeability has been increased due to an unidentified noxious agent. The process is reversible and leaves an unimpaired lung parenchyma in those patients in whom recovery is complete.

It is characterized clinically by a progressive and frequently incapacitating dyspnoea, and is essentially a chronic process with a course measured in years and a mortality of about $30 \%$. A diffuse nodulation similar to that of silicosis seems to be the earliest radiographic change. Later, denser confluent areas develop, giving the impression of a radiation outwards from the hila involving principally the lower two-thirds of the lung fields. The physical disability and clinical findings often seem disproportionately slight in the presence of these radiological appearances. The characteristic finding is evidence of alveolarcapillary block without airway obstruction, and, though there is some overall limitation of respiratory function, usually this is not severe. 
Possible techniques for future investigation are indicated and therapeutically a trial of proteolytic enzymes is suggested.

We are greatly indebted to Dr. L. W. Hale for allowing us to quote from the early case notes, to Dr. F. D. M. Hocking for the necropsy, to P. J. Chellew, Esq., H.M. Coroner for West Cornwall, for permission to publish these findings, and to Professor J. Gough for the giant lung section. We also thank Dr. T. A. B. Mason and his staff for the many radiographs taken, Dr. R. W. Spencer and Mr. D. R. James for the chemical analysis, Dr. J. R. Butler for the spectrographical analysis, and Dr. K. F. G. Hosking for excluding radioactivity. Finally, we record our gratitude to Dr. Lloyd Rusby and Professor R. A. Willis for reading the manuscript, and to Miss Phyllis E. Coleman for the photography.

\section{REFERENCES}

Borgström, K. E., Ising, U., Linder, E., and Lunderquist, A. (1960). Acta radiol. (Stockh.), 54, 97.
Burbank, B., Morrione, T. G., and Cutler, S. S. (1960). Amer. J. Med., 28, 1002.

Carlson, D. J., and Mason, E. W. (1960). Amer. J. clin. Path., 33, 48.

Edmondson, W. R., and Gere, J. B. (1960). Ann. intern. Med., 52, 1310.

Fraimow, W., Cathcart, R. T., Kirshner, J. J., and Taylor, R. C. (1960a). Amer. J. Med., 28, 458.

- and Taylor, R. C. (1960b). Ann. intern. Med., 52, 1177.

Furst, W. E., Bell, B. M., and Irons, G. V. Jr. (1960). Amer. J. Med., 28, 453.

Hall, G. H. (1959). Lancet, 1, 750.

Hall, G. F. M. (1960). lbid., 1, 1383.

Hamperl, H. (1947). Verh. dtsch. path., 83, Suppl.

Jones, C. C. (1960). Amer. J. Med., 29, 713.

Levinson, B., Jones, R. S., Wintrobe, M. M., and Cartwright, G. E. (1958). Blood, 13, 959 .

McDowell, C., Williams, S. E., and Hinds, J. R. (1959). Aust. Ann. Med., 8, 137.

Pearse, A. G. E. (1955). J. Path. Bact., 70, 554.

Plenk, H. P., Swift, S. A., Chambers, W. L., and Peltzer, W. E. (1960). Radiology, 74, 928.

Rosen, S. H., Castleman, B., and Liebow, A. A. (1958). New Engl. J. Med., 258, 1123.

Schoen, I., Reingold, I. M., and Meister, L. (1958). Ann. intern. Med., 49, 687.

Snider, T. H., Wilner, F. M., and Lewis, B. M. (1960). Ibid., 52, 1318.

Williams, G. E. G., Medley, D. R. K., and Brown, R. (1960). Lancet, 1,1385 . 